\title{
Citrullinemia Type I - A Case Report
}

\author{
F MOHSIN $^{\mathrm{a}}$, S MAHBUBA ${ }^{\mathrm{b}}, \mathrm{TBEGUM}^{\mathrm{c}}$, NC SAHA $^{\mathrm{d}}, \mathrm{KAZAD}^{\mathrm{e}}, \mathrm{N} \mathrm{NAHAR}^{\mathrm{f}}$
}

\begin{abstract}
Summarty:
Citrullinemia type I (CTLN1) is an inherited urea cycle disorder where the enzyme argininosuccinate synthetase is deficient. It can lead to recurrent hyperammonemic crisis that may result in permanent neurological sequelae, even death. Vomiting in patients with urea cycle disorders may either be the result or cause of acute hyperammonemia, particularly if due to an illness that leads to catabolism. Therefore, age-appropriate common etiologies of vomiting must be considered when evaluating these patients. We present
\end{abstract}

\section{Introduction:}

Citrullinemia (CTLN), a rare autosomal recessive disorder, is characterized by the accumulation of citrulline and hyperammonemia caused by a deficiency in argininosuccinate synthetase (AS), the third enzyme in the urea cycle that catalyzes the formation of argininosuccinate from citrulline and aspartate. ${ }^{1}$ Two clinically and genetically distinct form of citrullinemia has been identified. The classic form (type I, CTLN 1) is due to deficiency of AS enzyme which has a severe or neonatal form and a subacute or mild form. Citrullinemia type II (CTLN2) is due to deficiency of mitochondrial

a. Dr. Fauzia Mohsin, Associate Professor, Department of Paediatrics, BIRDEM General Hospital and Ibrahim Medical College, Dhaka, Bangladesh

b. Dr. Sharmin Mahbuba, Senior Medical Officer, Department of Paediatrics, BIRDEM General Hospital

c. Prof. Tahmina Begum, Professor and Head, Department of Paediatrics, BIRDEM General Hospital and Ibrahim Medical College

d. Dr. Narayan Chandra Saha, Associate Prof. of Paediatric Neurology, National institute of Neuroscience, Dhaka, Bangladesh

e. Prof. Kishwar Azad, Senior Honorary Consultant, Department of Paediatrics, BIRDEM General Hospital and Ibrahim Medical College

f. Prof. Nazmun Nahar, Department of Paediatrics, BIRDEM General Hospital and Ibrahim Medical Colllege

Address of Correspondence: Dr. Fauzia Mohsin, Department of Paediatrics, BIRDEM General Hospital and Ibrahim Medical College, BIRDEM General Hospital-2 (Mahila O Shishu), 1/A, Ibrahim Sharani, Shegunbagicha, Dhaka-1000, Bangladesh, Tel: 880-1713063141 (Mobile), 880-2-8855032 (H), Fax: 880-2966781, Email: fauzia_mohsin@yahoo.com

Received: 25 January, 2014 Accepted: 23 October, 2014 a case of a 2 year 5 month old female child with CTLN1 who had a history of frequent vomiting after the age of one year and some recent neurological manifestations like excessive crying and lethargy and one episode of unconsciousness. Investigations revealed high level of ammonia. Amino acid profile using tandem mass spectrometry showed markedly increased plasma level of citrulline. After administration of sodium benzoate and protein restricted diet there was dramatic improvement of all the symptoms.

(J Banagladesh Coll Phys Surg 2015; 33: 98-100)

transport protein named citrin. Citrullinemia due to citrin deficiency (CTLN2) is caused by mutations in chromosome 7q21.3. ${ }^{2}$ Citrin deficiency leads to a failure to shuttle aspartate and glutamate to and from the mitochondrion, leading to a mild hyperammonemia . ${ }^{3}$ CTLN2 is characterized by a less pronounced elevation of plasma citrulline. It has neonatal form with neonatal intrahepatic cholestasis and adult-onset form. Here we present a case of a 2 year 5 month old female child with CTLN1 who had a history of frequent vomiting after the age of one year and some recent neurological manifestations like excessive crying and lethargy and one episode of unconsciousness. She was referred to BIRDEM hospital as a case of suspected diabetic ketoacidosis (DKA)

\section{Case Report:}

A 2 year 5 month old female child, $3^{\text {rd }}$ issue of non consanguineous parents was referred to BIRDEM hospital as a suspected case of diabetic ketoacidosis (DKA). She had recurrent, nonprojectile vomiting since one year of age and was treated with anti emetic and antibiotic on several occasions. For last few weeks patient had developed increased vomiting, lethargy and excessive crying for which she was admitted in a local hospital. There she became unconscious after taking sedative on an attempt to do a CT scan of brain. She regained consciousness after one day but became more lethargic. On investigation she had thrombocytosis (platelet count 6,29,000/cu mm),hyperglycemia (blood glucose $12.1 \mathrm{mmol} / \mathrm{L})$, raised SGPT(101mU/L) and metabolic acidosis. Urine routine examination showed pus cell and culture yielded growth of E Coli. She was treated there with intravenous fluid, anti emetic and 
parenteral antibiotic initially as a case of urinary tract infection (UTI) but as her condition deteriorated and diabetic ketoacidosis (DKA) was suspected, she was referred to BIRDEM hospital for further management. There was no history of fever, convulsion and trauma. Her birth history was uneventful. She was on exclusive breast feeding upto 7 months of age and then complimentary feeding with khichury was started. Her bowel and bladder habit was normal. There was history of one sib death at 11 months of age due to fever, convulsion with excessive crying. On admission in BIRDEM hospital, she was found conscious, lethargic, afebrile, mildly pale, anicteric and non dehydrated. There was no facial dysmorphism. Vital parameters were normal. Eye and ear, nose, throat examinations were normal. Signs of meningeal irritation were absent. Bed side capillary blood glucose was $7.7 \mathrm{mmol} / \mathrm{L}$ ( normal $<7.8 \mathrm{mmol} / \mathrm{L}$ ), urine for glucose and ketone were absent. Anthropometric measurements were normal for her age and sex. She had mild developmental delay. Her muscle tone was reduced, muscle bulk and power were normal. All reflexes and sensation were intact, gait was normal. She had non tender hepatomegaly, $3 \mathrm{~cm}$ from subcostal margin in midclavicular line. All other systems revealed normal findings. Investigations revealed: leucocytosis (Total WBC count 17,600/cu mm), thrombocytosis (platelet count 5,79,000/cu mm), raised level of serum transaminases (ALT $316 \mathrm{U} / \mathrm{L}$, AST $288 \mathrm{U} / \mathrm{L}$ ), with normal bilirubin, alkaline phosphatase, prothombin time and serum albumin, normal lipid profile and normal level of serum creatinine. Her fasting, random blood glucose and $\mathrm{HbA} 1 \mathrm{c}$ were normal thus excluding diabetes mellitus. There was respiratory alkalosis with normal anion gap. Her serum ammonia level was 307ìmol/L (normal range 9-30 ìmol/L), blood urea level was $16 \mathrm{mg} /$ $\mathrm{dl}$ (normal range 10-50mg/dl). The citrulline level on amino acid profile using tandem mass spectrometry (TMS) was $908.76 \mu \mathrm{M}$ (normal range 4-45 $\mu \mathrm{M}$ ), which was very high. Urine routine examination was normal and culture yielded no growth. Ultrasonogram of whole abdomen showed increased hepatic parenchymal echogenicity. Initially we thought of sepsis with some inborn error of metabolism and after getting all the reports the patient was finally diagnosed as a case of citrullinemia typeI. Patient was initially managed by intravenous fluid, Anti emetic, parenteral antibiotic was continued. After getting the biocemichal reports, protein restricted diet, sodium benzoate powder with food and carnitine supplementation was advised. Consultation from paediatric neurologist was also taken. Parents were counseled about the disease process, its prognosis and management. Genetic counseling was also done. Parents were advised to come for regular follow up. After one month, there was significant improvement in patient's general well being. The vomiting had stopped. Patient was alert, well and playful. Serum ammonia level came down to 68 ìmol/L (normal range 9-30 ìmol/L) and liver enzymes were normal (ALT $40 \mathrm{U} / \mathrm{L}$ and AST $37 \mathrm{U} / \mathrm{L}$ ).

\section{Discussion:}

Citrullinemia, an autosomal recessive disorder, occurs in 1:57,000 births ${ }^{4}$ and causes a dramatic elevation of plasma citrulline Following the recent report by Kobayashi et al, who identified the citrin gene responsible for adult-onset type II CTLN. CTLN is now classified as CTLN1 and CTLN2. Citrullinemia type I is caused by a mutation in the AS gene located on chromosome 9q34. ${ }^{5}$ Most patients with classical CTLN1 present with symptoms during the early neonatal period with acute hyperammonemia and life threatening encephalopathy. Seizures progressing to coma and death are typical in untreated patients. ${ }^{6}$ The outcome is poor with significant risk of neurological damage or demise. In the subacute or mild form, clinical findings such as failure to thrive, frequent vomiting, developmental delay and dry, brittle hair appear gradually after one year of age. Acute hyperammonemia, triggered by intercurrent catabolic state, may bring the diagnosis to light as occurred in our patient. ${ }^{5}$ There are also reports of women with onset of severe symptoms during pregnancy or in the postpartum period. ${ }^{7}$ Individuals remaining asymptomatic up to at least ten years of age have been reported; it seems possible that they may remain asymptomatic throughout life. ${ }^{8,9}$ In CTLN1 the plasma level of citrulline is markedly elevated, usually 50-100 times normal. Urinary excretion of orotic acid is moderately increased. The diagnosis is further confirmed by enzyme assay in cultured fibroblasts or by DNA analysis. ${ }^{5,10,11}$ Newborn screening by tandem mass spectrometry (TMS) using a dried blood spot can detect elevated level of citrulline. Prenatal diagnosis is possible with the assay of the enzyme activity in the cultured amniotic cells or by DNA analysis of chorionic villi biopsy. ${ }^{4,5}$ Treatment of acute hyperammonemia in an infant includes provision of adequate calorie, fluid 
and electrolyte intravenously, adding minimal amounts of protein preferably as a mixture of essential amino acids, giving priming dose and then continuing infusion of sodium benzoate, sodium phynylacetate, arginine hydrocholoride, peritoneal dialysis or hemodialysis may also be needed in severe case. ${ }^{12,13}$

Our patient had the mild form of CTLN1 and was successfully managed by protein restricted diet, oral sodium benzoate and carnitine supplementation. Sodium benzoate is given to conjugate glycine, a major amino acid that contributes ammonia to the urea cycle, forming hippurate, which is subsequently excreted in the urine. Carnitine supplementation is recommended because benzoate may cause carnitine deficiency. ${ }^{5}$ She initially had UTI and sepsis which along with chronic cerebral edema might be responsible for exacerbation of her symptoms. Our patient had respiratory alkalosis which strongly suggests a urea cycle defect. It is the result of hyperventilation due to stimulation of the central respiratory drive by hyperammonemia. ${ }^{14}$ The initial hyperglycaemia with metabolic acidosis could be explained by UTI and the stress of acute infection. Ammonia can cause swelling of hepatic mitochondria, leading to increase in serum transaminase, as found in our patient. Our patient had the mild form of CTN1, therefore the prognosis is better than that of symptomatic neonates. These patients usually do well if treated properly. ${ }^{5}$ Catabolic states (infection, fasting) should be avoided or treated vigorously. They need close monitoring of growth, development and nutritional indices (blood albumin, pH electrolytes, amino acids, zinc). Long term care of these patients is best achieved by a team of experienced professionals (physician specialist, nutritionist, neurologist and geneticist).

In conclusion, we describe a case of CTLN1 which can lead to recurrent hyperammonemic crisis that may result in permanent neurological sequelae or even death. Therefore, this case report shows the importance of biochemical and metabolic investigations, to reach an early and definitive diagnosis and proper management of such cases.

\section{References:}

1. Thoene JG. Citrullinemia type 1.In:Pagon RA, Bird TD, Dalon CR,Stephens K,editors.Gene Reviews. Seattle,WA:University of Washington;1993.
2. Kobayashi K, Sinasac DS, Iijima M, Boright AP, Begum L,Lee JR et . The gene mutated in adult-onset typeII citrullinemia encodes a pytative mitochondrial carrier protein. Nat Genet 1999;22:159-63.

3. Iijima M, Jalil a, Begum L,Yasadu T, Yamaguchi N, Xian Li M, Kawada N, Endou H ,Koboyashi K, Saheki T. Pathogenesis of adult onset type II cetrullinemia caused by deficiency of citrin, a mitochondrial solute carrier protein: tissue and subcellular localization of citrin.Adv. Enzyme Regul 2001;41:325-342.

4. Perkin Elmer. Citrullinemia. In:Handbook of Metabolic and Other inherited Disorders.Bridgeville;2010:37-38.

5. Rizwani I, Yudkoff M. Urea Cycle and Hyperammonemia (arginine, Citrulline, Ornithine) In: Kliegman RM, Stanton BF St. Geme JW, Schor NF, Behrman RE, editors. Nelson Textbook of Pediatrics. $19^{\text {th }}$ ed. Philadelphia (PA): Elsevier; 2012: 447-453.

6. Maestri NE, Clissoid DB,Bruusilw SW. Long-term survival of patients with argininosuccinate synthase deficiency. J Pediatr 1995;127:929-35.

7. Gao H.Z, Kobayashi K, Tabata A, Tsuge H, Iijima M, Yasuda $\mathrm{T}$ et al. Identification of 16 novel mutations in the argininosuccinate synthase gene and genotypephenotype correlation in 38 classical citrullinemia patients. Hum Mutat 2003;22:24-34.

8. Haberle J, Pauli S, Linnebank M, Klejjer W. J, Bakker H.D, Wanders R.J, Harms E, Koch H. J. Structure of the human argininosuccinate synthase gene and an improved system for molecular diagnostics in patients with classical and mild citrullinemia. Hum Genet 2002;110:327-333.

9. Haberli J. Pauli S, Schmidt E, Schulze-Elilfing B, Berning C, Koch H. G. Mild citrullinemia in Caucassians is an allelic variant of argininosucccinate synthase deficiency (citrullinemia type 1). Mol. Genet Metab 2003;80:302306.

10. Kim I. S, Chang_Ki C.S, Kim J.W, Lee M, Jin D. K, Lee S.Y. Characterization of late-onset citrullinemia1 in a Korean patient: Confirmation by Argininosucccinate synthase gene mutation analysis. Journal of Biochemistry and Molecular Biology 2006;39:400-405.

11. ML Batshaw,UL Konecki, M Tuchman; Inborn errors of urea synthesis. In: Pediatric Neurology: Principles and Practice, $4^{\text {th }}$ Edn, Mosby-Elsevier $2006: 603-615$.

12. Summer M, Tuchman M. Proceedings of a consensus conference for the management of patients with urea cycle disorders. J Pediatr 2001;138:S6-S10.

13. Rhee Y, E,Heaton T, Keegan C, Ahmad A. Citrullinemia type 1 and hypertrophic pyloric stenosis in a 1 -month old male infant. Clinics and Practice 2013;3:3-5.

14. http;//emedicine.medscape.com/article/1174503-workup. 